\title{
Plasma vasopressin and blood pressure Studies in normal subjects and in benign essential hypertension at rest and after postural challenge
}

\author{
ROY DAVIES, MARY FORSLING, G BULGER, TANIA PHILLIPS \\ From Whittington and Royal Northern Hospitals and Middlesex Hospital Medical School, London
}

SUMMARY Plasma vasopressin levels were compared in three groups comprising normotensive, $\dot{\infty}$ mildly hypertensive, and more severely hypertensive patients, both under basal conditions and $N$ following an $85^{\circ}$ head-up tilt, a stimulus known to provoke vasopressin release in man. Vasopressin 0 levels increased two- to fivefold in all subjects after tilt; however, neither the basal levels nor the maximal levels attained at 45 to 60 minutes after tilt differed in the three groups. These data do not $c$ support the postulated role for vasopressin in the causation or perpetuation of non-accelerated $\frac{\sim}{\Phi}$ essential hypertension in man.

The renin-angiotensin-aldosterone system, the catecholamines, and arginine vasopressin are the factors known to influence pressure and volume homeostasis in man; of these, the renin-angiotensin system and, more recently, the catecholamines have been the subject of intensive study in the search for a causative agent in essential hypertension. Vasopressin, however, is unique among these factors in that it has a direct pressor effect on vascular smooth muscle and it directly influences plasma volume by its antidiuretic activity. It, therefore, seems an obvious hormone to incriminate in the causation or perpetuation of raised arterial pressure. Difficulties in the measurement of vasopressin in the plasma have impeded studies of its possible role in hypertension in man, but the recent development of sensitive radioimmunoassays ${ }^{1}$ has made studies like this one possible.

Some recent studies have only shown differences between normal and hypertensive patients when the humoral system under examination is stressed, for example catecholamines after dynamic exercise. ${ }^{2}$ Apparent hypovolaemia induced by manoeuvres such as head-up tilt, ${ }^{3}$ centrifugation, ${ }^{4}$ warming, ${ }^{5}$ lower body suction, ${ }^{6}$ and epidural anaesthesia ${ }^{7}$ is known to stimulate vasopressin release in man. Among these techniques head-up tilt provides the most convenient and reliable for clinical use. We present here dynamic data in subjects with normal blood pressure and with various levels of raised diastolic pressure comparing plasma vasopressin levels both under basal conditions and during a standardised $85^{\circ}$ head-up tilt.

Accepted for publication 1 March 1983

\section{Patients and methods}

Twenty-eight patients were studied and were divided into three groups according to their arterial pressures. Group A comprised nine normal subjects who were $\stackrel{\mathbb{2}}{2}$ under investigation for symptoms such as palpitation $\overrightarrow{\vec{O}}$ or atypical chest pain. None had any history of hyper- 3 tension, and all had diastolic blood pressures of 85. $\mathrm{mmHg}$ or less. This group comprised seven men and two women whose ages ranged from 29 to 59 years (mean age 43 years). Group B comprised 11 patients with mild to moderate essential hypertension (mean?age 41 years, range 23 to 59 years) of whom seven 3 . were men and four were women. Diastolic blood pressures in this group were in the range 90 to $109 \mathrm{mmHg}$ (mean diastolic blood pressure $101 \mathrm{mmHg}$ ). Group $\mathrm{C}_{\circ}^{\circ}$ comprised eight patients of whom four were men and four were women, their ages ranging from 27 to 63 음 years (mean age 49 years) with diastolic blood pressures of $110 \mathrm{mmHg}$ or above (mean diastolic blood $N$ pressure $119 \mathrm{mmHg}$ ).

As judged by the history, clinical examination, and $N_{\omega}$ conventional investigative procedures, none of the $\frac{\omega}{\sigma}$ patients had a secondary cause for hypertension nor any significant target organ damage. None of the patients had received any drugs in the preceding four $\stackrel{\infty}{\rightarrow}$ weeks, and all gave their informed consent to the $\tau$ study, which was approved by the Ethical Committee for Clinical Research. Arterial pressure was deter- $\mathbb{\mathbb { D }}$ mined by mercury sphygmomanometry using Korot- $\frac{O}{\mathbb{D}}$ koff phases I and IV. The blood pressure value $\frac{\varrho}{\sigma}$ observed at the third or subsequent clinic visit was 
used to allocate the patients to groups A, B, or C.

All patients were studied according to an identical procedure. They attended at 8.30 to $9.00 \mathrm{am}$ after abstaining from fluids, alcohol, and nicotine for at least 12 hours. After 60 minutes of supine rest, they were slowly tilted to the $85^{\circ}$ head-up position on an electrically operated tilt bed for 60 minutes. At the beginning of the rest period a small "Teflon" cannula was inserted into an antecubital fossa vein. Samples for plasma vasopressin, electrolytes, and osmolality were taken five minutes before tilt and then during tilt at $15,30,45$, and 60 minutes. Samples for vasopressin were separated immediately and deep frozen. Plasma vasopressin was determined by a radioimmunoassay based on the method of Chard and Forsling ${ }^{1}$ using iodinated vasopressin prepared by the lactoperoxidase method. ${ }^{8}$ Estimations were performed on plasma extracted with bentonite. ${ }^{9}$ Plasma osmolality and electrolytes were determined by routine analytical techniques. To avoid anxiety and to minimise the possibility of vasovagal syncope, a well known hazard of tilt, ${ }^{310}$ all patients were taken through the tilt procedure in a preliminary dummy run. Similarly, during the tilt, the patients were asked to avert their gaze during blood sampling. Blood pressure was determined throughout the procedure, and heart rate was monitored electrocardiographically. All results are expressed as mean \pm SEM; Student's $t$ test for paired data was employed to compare vasopressin levels before and after orthostasis. Between group comparisons of vasopressin levels at rest or after tilt were made using an unpaired Wilcoxon rank sum test. $\mathbf{P}<0.05$ was taken as the minimal value for statistical significance.

\section{Results}

The individual basal values for vasopressin together with the maximum value attained on tilt are shown in the Figure.

\section{BASAL VASOPRESSIN VALUES}

The basal values for vasopressin in group $A$ ranged from 0.3 to 2.2 microunits $/ \mathrm{ml}$, those in group B from 0.1 to 2.0 microunits $/ \mathrm{ml}$, and those in group $C$ from 0.3 to 1.9 microunits $/ \mathrm{ml}$. The mean basal values of $1.24 \pm 0.26,0.95 \pm 0.18$, and $0.99 \pm 0.21$ microunits $/ \mathrm{ml}$ observed in groups A, B, and C, respectively, did not differ significantly one from the other (Wilcoxon rank sum test).

\section{RESPONSE OF VASOPRESSIN TILT}

Vasopressin rose in all subjects, maximum values being observed at 45 to 60 minutes after tilt. The mean values observed during tilt were $2.72 \pm 0.36$, $3.38 \pm 0.49$, and $2.15 \pm 0.35$ microunits $/ \mathrm{ml}$ in groups

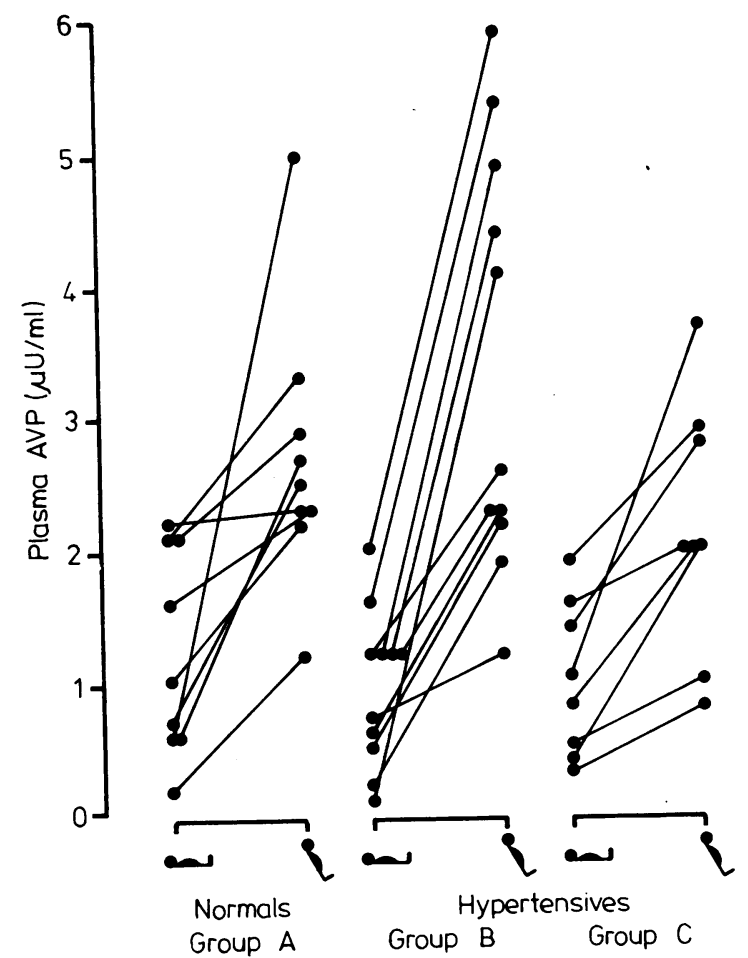

Fig. Effect of tilt on plasma vasopressin levels in the three groups studied.

A, B, and C, respectively. These values were all significantly greater than the corresponding basal values (Student's paired $t$ test, $t$ varies from 3.37 to 5.04). The maximum values observed during tilt in groups A, B, and C did not differ significantly from each other.

\section{RESPONSES OF OTHER VARIABLES}

Plasma osmolality and serum electrolytes did not differ significantly in the three groups under basal conditions or after tilt. Heart rate increased in all subjects after tilt and in the three groups there was a slight but variable fall in systolic and a slight but variable rise in diastolic pressure in response to tilt.

\section{Discussion}

A possible role for vasopressin in hypertension was first suggested in 1895 , when Oliver and Schäfer ${ }^{11}$ reported the pressor effects of a pituitary extract injected into animals. In 1937, Page and Sweet ${ }^{12}$ showed that hypophysectomy reduced arterial pressure in experimental renal hypertension in animals, while Ellis and Grollman ${ }^{13}$ in 1949 found enhanced antidiuretic activity in the urine of both hypertensive 
dogs and patients with severe hypertension. The studies of Möhring and his co-workers ${ }^{14-16}$ rekindled interest in vasopressin as a pressor hormone with a possible role in hypertension when they showed that plasma vasopressin levels were raised in various forms of spontaneous and induced hypertension in rats. Their careful studies showed higher levels of vasopressin during the malignant phase of hypertension in their animals and, furthermore, that a vasopressin antibody prevented the development of vascular lesions in certain forms of experimental hypertension in rats. Studies in man, however, have presented conflicting evidence. In 1976, two independent groups suggested a possible role for vasopressin in human hypertension. Khokhar and Slater ${ }^{17}$ showed increased urinary excretion of vasopressin in mildly hypertensive young men, while Padfield et al. ${ }^{18}$ reported raised plasma vasopressin levels in a group of patients with malignant hypertension. This latter group have recently expanded their studies ${ }^{19}$ to include normal volunteers, subjects with mild to moderate essential hypertension, and patients with the syndrome of inappropriate antidiuretic hormone secretion. They found only minor changes in arterial pressure when vasopressin was infused at rates sufficient to produce plasma levels spanning those found in malignant hypertension and furthermore they found that arterial pressures were not raised in patients with inappropriate antidiuretic hormone secretion. They concluded that neither acute nor chronic vasopressin excess appears to contribute to blood pressure regulation in man.

Our study adds further to the data already available in man in that we could not show any difference in plasma vasopressin levels across the range of normal to much raised arterial pressures. In contrast to the work of Padfield et al., 1819 our study was confined to patients lacking significant target organ damage. In malignant hypertension, pronounced volume depletion together with renin-angiotensin activation might arguably cause raised vasopressin levels such as found in Padfield's patients.

In this present study we have also confirmed our earlier observations that head-up tilt reliably provokes increases in vasopressin levels ${ }^{320}$; and by providing a dynamic assessment of vasopressin responsiveness, we are able to expand upon simple comparisons of basal vasopressin levels. Thus, we have failed to show any difference in vasopressin levels at rest, or in response to a challenge known to promote release in the three groups of patients studied, and we suggest that vasopressin is unlikely to be important in the aetiology of essential benign hypertension.

We thank Dr T Dormandy and colleagues in the Department of Biochemistry at The Whittington Hospital for their enthusiastic co-operation.

\section{References}

1 Chard T, Forsling ML. In: Antoniades HN, ed. Hor- $\overrightarrow{\overline{\vec{F}}}$ mones in human blood. Cambridge, Massachusetts: Har-O vard University Press, 1976: 488-516.

2 Phillipp T, Distler A, Cordes U. Sympathetic nervous system and blood pressure control in essential hyperten- $\overrightarrow{\overparen{D}}$ sion. Lancet 1978; ii: 959-63.

3 Davies R, Slater JDH, Forsling ML, Payne N. The response of arginine vasopressin and plasma renin to $\overrightarrow{-}$ postural change in normal man, with observations on. syncope. Clin Sci Mol Med 1976; 51: 267-74.

4 Rogge JD, Moore WW, Segar WE, Fasola AF. Effect of $+\mathrm{Gz}$ and $+\mathrm{Gx}$ acceleration on peripheral venous $\mathrm{ADH}$ levels in humans. $\mathcal{F}$ Appl Physiol 1967; 23: 870-4.

5 Moore WW, Segar WE. The effects of change in position. and ambient temperature on blood $\mathrm{ADH}$ in the human? [Abstract]. Fed Proc 1966; 25: 253.

6 Rogge JD, Moore WW. Influence of lower body negative $\infty$ pressure on peripheral venous ADH levels in man. $\mathcal{F}$ 윽 Appl Physiol 1968; 25: 134-8.

7 Cochrane JPS, Forsling ML, Menzies Gow N, Le $c$ Quesne LP. Arginine vasopressin release following sur- $\bar{\Phi}$ gical operations. Br $\mathcal{f}$ Surg 1981; 68: 209-13.

8 Karonen SL, Mörsky P, Siren M, Senderling Y. An $\vec{\varnothing}$ enzymatic solid-phase method for trace iodination of pro-. teins and peptides with 125-Iodine. Anal Biochem 1975; 67: $1-10$.

9 Skowsky WR, Rosenbloom AA, Fisher DA. Radioimmunoassay measurement of arginine vasopressin in serum; development and application. 7 Clin Endocrinol 응 Metab 1974; 38: 278-87.

10 McMichael J, Sharpey-Schäfer EP. Cardiac output in $\overrightarrow{\vec{\sigma}}$ man by a direct Fick method; effects of posture, venous 3 pressure change, atropine, and adrenaline. $\mathrm{Br}$ Heart $\mathcal{F}$ 1944; 6: 33-40.

11 Oliver G, Schäfer EA. On the physiological action of extracts of pituitary body and certain other glandular organs. F Physiol (Lond) 1895; 18: 277-9.

12 Page IH, Sweet JE. The effect of hypophysectomy on arterial blood pressure of dogs with experimental hyper- 3 . tension. Am F Physiol 1937; 120: 238-45.

13 Ellis ME, Grollman A. The antidiuretic hormone in the urine in experimental and clinical hypertension. Endocrinology 1949; 44: 415-9.

14 Möhring J, Möhring B, Petri M, Haack D. Is vasopressin involved in the pathogenesis of malignant deoxycorticosterone hypertension in rat? Lancet 1976; i: 170-3. N

15 Möhring J, Möhring B, Petri M, Haack D. Vasopressorrole of $\mathrm{ADH}$ in the pathogenesis of malignant DOC hypertension. Am $\mathcal{F}$ Physiol 1977; 232: F260-9.

16 Möhring J, Möhring B, Petri M, Haack D. Plasma vasopressin concentrations and effects of vasopressin antiserum on blood pressure in rats with malignant twokidney Goldblatt hypertension. Circ Res $1978 ; 42: 17-22$.

17 Khokhar AM, Slater JDH. Increased renal excretion of ${ }^{+}$ arginine vasopressin during mild hydropenia in young men with mild essential benign hypertension. Clin Sci 음 Mol Med 1976; 61 (suppl 3): 691s-4s.

18 Padfield PL, Brown JJ, Lever AF, Morton JJ, Robertson $\mathbb{D}$ JIS. Changes of vasopressin in hypertension: cause or $\frac{\varrho}{\sigma}$
effect? Lancet 1976; i: $1255-7$.

19 Padfield PL, Brown JJ, Lever AF, Morton JJ, Robertson $\varnothing$ 
JIS. Blood pressure in acute and chronic vasopressin excess. $N$ Engl F Med 1981; 304: 1067-70.

20 Davies R, Forsling ML, Slater JDH. The interrelationship between the release of renin and vasopressin as defined by orthostasis and propranolol. $f$ Clin Invest
1977; 60: $1438-41$.

Requests for reprints to Dr Roy Davies, Cardiac Department, St Mary's Wing, Whittington Hospital, Highgate Hill, London N19 5NF. 